\title{
QUALIDADE MICROBIOLÓGICA DA ÁGUA DO RIO SÃO LOURENÇO, SÃO LOURENÇO DO SUL, RIO GRANDE DO SUL
}

\author{
F.C. da S. V asconcellos, J.R.V. Iganci, G .A. Ribeiro
}

UniversidadeFederal dePel otas, Instituto deBiologia, Campus Universitário, s/ oㅡ, CEP 96010-900, Pelotas, RS, Brasil. E-mail: fernandacsv@gmail.com

RESUMO

\begin{abstract}
O RioSão Lourençonasceno interior dacidadedeSão Lourenço doSul, centro-sul do Rio Grande do Sul edesemboca na Laguna dos Patos, recebendo ao longo deseu percurso resíduos agrícolas eefluentesdomésticossemtratamento prévio. Comoobjetivodeanalisar aqualidademicrobiológica daágua desserio, foram coletadas amostras detrês pontos pré-estabelecidos, entremaio de 2004 a abril de2005. Paraaanálisemicrobiológica, osmei osdecultura utilizadosforamo cal dolactosado (CL) para o testepresuntivo, caldolactosebileverdebrilhante(CLBVB) para o testeconfirmativo decoliformestotais(CT) eo cal doEC paraotesteconfirmativo decoliformestermotolerantes. Com os resul tad os obtidos constatou-se quetodos os pontos estavam impróprios para bal neabilidade devido à alta contaminação por coliformes totais e termotolerantes, em 93\% das amostras analisadas.
\end{abstract}

PALAVRAS-CHAVE:M icrorganismostermotolerantes, monitoramento ambiental, Escherichiacoli.

\section{ABSTRACT}

MICROBIOLOGICAL WATER QUALITY OF THE SÃO LORENÇO RIVER, SÃO LOURENÇO DO SUL, RS, BRAZIL. The São Lourenço River is born in the countryside of São Lourenço do Sul city, Central Southern Rio Grande do Sul, and discharges into Laguna dos Patos, receiving throughoutits passageagricultural residuals, nontreated wastewater from residential and commercial areas. With theobjectiveto analyzethe microbiological quality water of theriver, samples were collected from threeestablished points, between M ay 2004and A pril 2005. For themicrobiological analyzes, thefollowing culturemediawereemployed : LactoseBroth for thepresuntivetest, Brilliant green lactosebileBroth for theconfirmativetest of total colliforms and EC Broth for confirmative test of thermotolerant col iforms. From theresults wecan concludethat the water collected from all points wasinappropriatefor drinking or recreation dueto contamination of $93 \%$ of samples with thermotolerant colliforms.

KEY WORDS: Thermotolerant microorganisms, environment monitoring, Escherichia coli.

\section{INTRODUÇÃO}

Indicadores microbiológicos têm sido utilizados mundialmente para verificar a contaminação decorpos d'água por resíduos humanos. Tipicamente são utilizadosorganismosquesãoencontradosemelevadasconcentraçõesemfezeshumanas. Osindicadores geralmente utilizados incluem coliformes totais, coliformes fecais, Escherichia coli eenterococci ( SHIBATA et al., 2004). As bactérias do grupo coliforme são indicadoras de contaminação fecal, ou seja, indicam seumaáguafoi contaminada por fezese, em decorrência, seapresenta uma potencialidade para transmitir doenças (Von Sperling, 1996). Segundo Barrell et al. (2002), o critério para queas bactérias sejam consideradasideais, indicadoras depoluição deorigemfecal, équeestejam presentes em grandenúmero nas fezes humanas e de animais; também devem estar presentes em efluentes residuais, serem detectáveis por mé todos simples e não devem estar presentes em água limpa e serem exclusivamente de origem fecal. Um membro do grupo dos coliformes, E. coli, satisfaz a maior parte destes critérios e sua presença em amostras deágua podeindicar a contaminação por outros patógenosintestinais. Entretanto, aausênciadeE .coli nem sempre significa a não existência de outros patógenos intestinais. E. coli é o único biótipo da família Enterobacteriaceaequepodeser considerado exclusivamente de origem fecal.

O Rio São Lourenço apresenta curso de água permanente, extenso comprimento navegável, grande largura (mais de 50m em vários pontos) e desemboca na Laguna dos Patos (RINGUelet, 1966). As nascentes do Rio São Lourenço encontram-se na Serra 


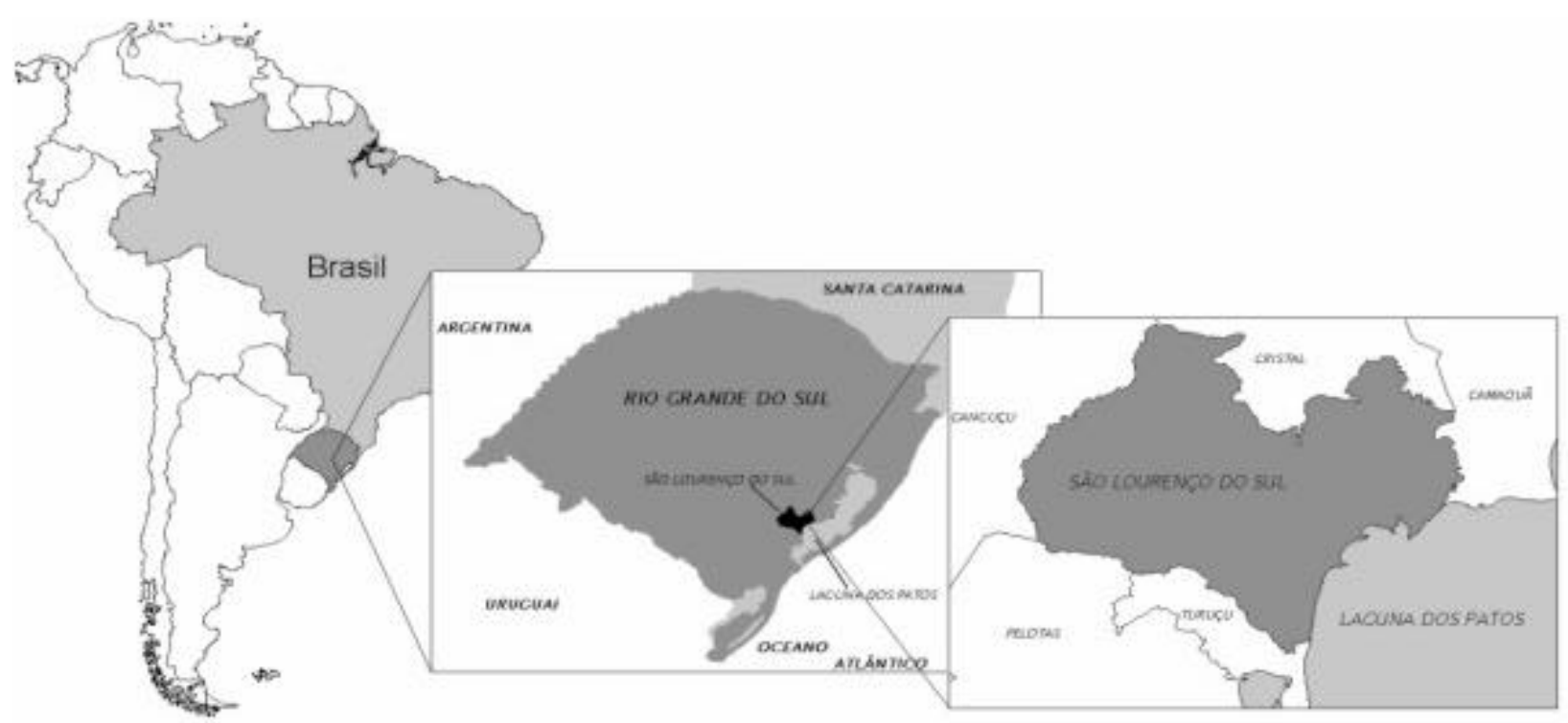

Fig. 1 - Localização geográfica da Cidade deSão Lourenço do Sul .

dosTapes, no interior do M unicípio do São Lourenço do Sul, localizado no centro-sul do RS, Brasil com distânciade190kmdePortoA legre(Fig. 1), naencosta dosudeste, tendosuadesembocaduranaLagunados Patos pela margem esquerda, guarnecida de rochas graníticas datadas do período Pré-Cambriano (CosTA, 1999). Recebe também ao longo de seu percurso resíduos agrícolas e efluentes domésticos sem tratamento prévio, o que pode comprometer a qualidade microbiológica desterio.

O escoamento superficial, durante o período de chuva, éofator quemaiscontribui paraamudançada qualidade microbiológica da água. A presença de coliformes nas amostras de água de mananciais, segundo A mARAL et al. (2003), tem relação direta com a presença de chuva, devido ao arraste de excretas humanas e animais. A ausência de tratamento favorece o alto nível de contaminação.

O objetivo destetrabal ho foi analisar a qual idade microbiológica daágua no Rio São Lourenço, em três estações decoletas pré-estabelecidas, através da pesquisa do grupo coliforme, no período de um ano.

\section{MATERIAL E MÉTODOS}

As 3 estações de coletas foram distribuídas ao longo do curso do rio de acordo com critérios de alta e baixa influência antrópica (BYamuKama et al., 2005). A primeira estação de coleta (Ponto 1) foi situada acima da barragem decaptação deágua para o abastecimentodaCidadedeSãoLourençodoSul.A segunda estação decoleta(Ponto 2) foi estabel ecidaemuma região próximo ao centro dacidade, ondeo rio recebe uma grandequantidadederesíduosprovenientes de esgoto doméstico ea terceira estação de coleta (Ponto 3) tambémlocaliza-seem região urbanadacidade, em direção à Laguna dos Patos (Fig. 2) .

Para a coleta das amostras, frascos esterilizados foram mergulhados contra a correnteza até uma profundidade em torno de $20 \mathrm{~cm}$, de modo a coletar um volume de água superior a $100 \mathrm{~mL}$, deixando um espaçolivrenofrasco paraagitaçãoantes deprocessar as análises (SOARES \& MAIA, 1999). Todas as amostras foramidentificadascomosrespectivoslocaisdecoleta e acondicionadas em bolsa térmica para o transporte até o Departamento de Microbiologia eParasitologia (DEMP) da Universidade Federal de Pelotas (UFPel) não ultrapassando olimitede $24 \mathrm{~h}$ para realização dos exames bacteriológicos.

No laboratório, assepticamente, os vidros foram agitadoseabertos, ecomuma pi peta estéril foi retirado $1 \mathrm{~mL}$ da amostra de água e transferido para um tubo contendo $9 \mathrm{~mL}$ deáguapeptonada $0,1 \%$, homogeneizouse o conteúdo por agitação e com outra pipeta estéril transferiu-se $1 \mathrm{~mL}$ da diluição $10^{-1}$ para diluição $10^{-2} \mathrm{e}$ assim sucessivamente até a diluição $10^{4}$. Depois de real izadas as diluições, foi colocado $1 \mathrm{~mL}$ de amostra em cada tubo ( 3 tubos por diluição) contendo caldo lactosado, com tubos deDurham emseu interior, para o teste presuntivo. A samostrasforam incubadasa $35^{\circ}$ C por 48h. Foram considerados resultados positivos, aqueles queapresentaramformação degás dentro dos tubos de Durham eturbidez do meio. A partir destes resultados, foi realizada a prova de confirmação de coliformes totais, utilizando cal do lactose bile verde brilhantecom tubos de Durham. A inoculação foi feita por meio da transferência de uma a duas gotas de 


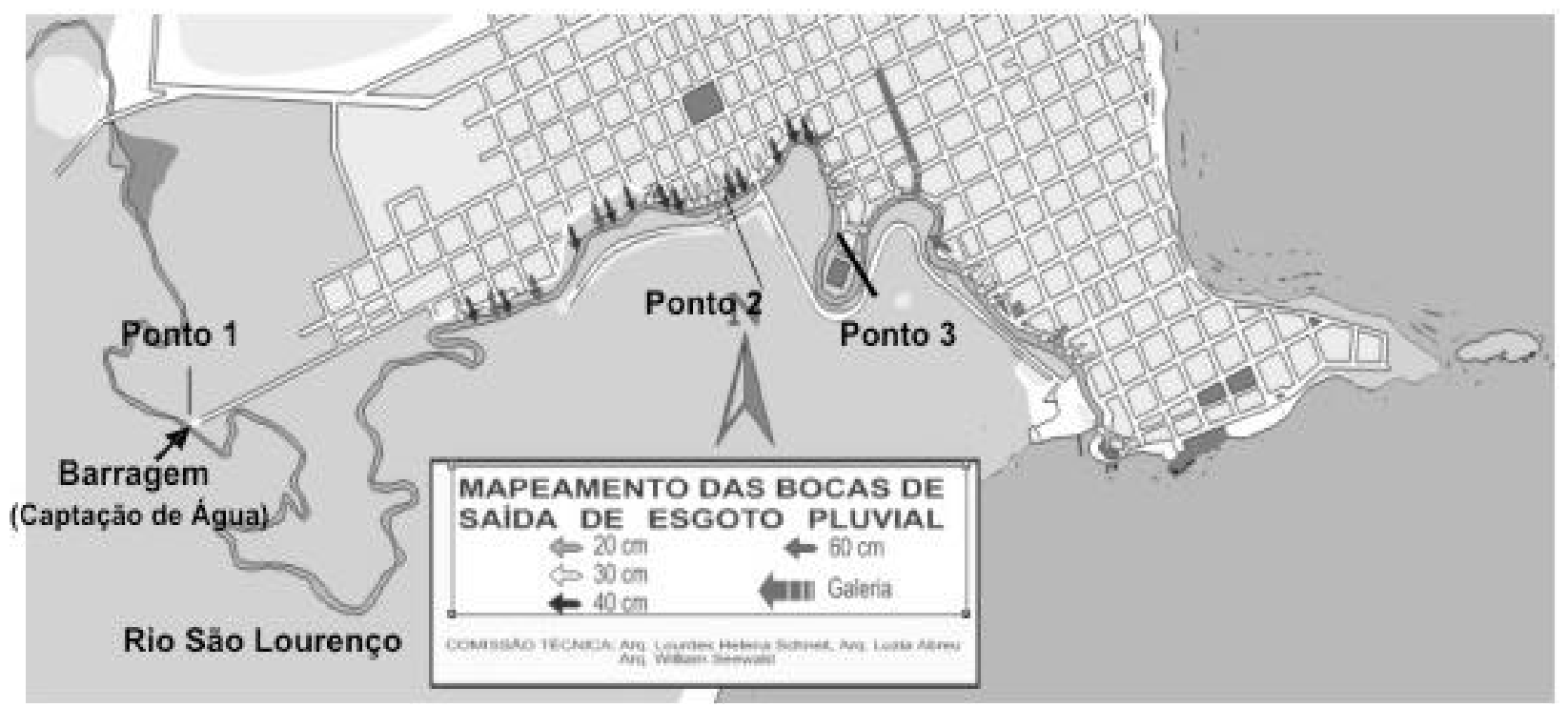

Fig. 2 - Localização das estações de coleta de água no Rio São Lourenço, na Cidade de São Lourenço do Sul, RS. Mapeamento das saídas de esgoto pluvial.

material retirado dos tubos positivos, com auxílio de uma al ça de platina. As amostras foram incubadas a $35^{\circ} \mathrm{C}$ por $48 \mathrm{~h}$. Foram considerados positivos, os tubos queapresentaram turbidez e gás dentro dos Durham. Destes tubos positivos transferiu-se com a alça de platina uma a duas gotas para tubos contendo Caldo EC com tubos de Durham em seu interior, e foram incubados em banho de água regulado a $44,5^{\circ} \mathrm{C}$ por $48 \mathrm{~h}$. A pós esteperíodo, observou-sea presença degás eturbideznomeio, sendoqueestesforamconsiderados positivos para bactérias coliformes termotolerantes. Os resultados foram expressos em valores de número mais provável (NMP) de coliformes termotolerantes/ $100 \mathrm{~mL}$ (SILva et al., 1997).

\section{RESULTADOSE DISCUSSÃO}

Os valores do número mais provável (NMP), de coliformes totais e termotolerantes encontrados nas amostras anal isadas estão representados na Tabela 1.

Em todos os pontos de coletas anal isados, podemos constatar que as águas do Rio São Lourenço, segundo a Resolução n 357 do CON AMA (17/ 03/ 2005), são impróprias para o consumo humano ou animal, a qual estabeleceum limitemáximo de 1.000 coliformestermotolerantes/ $100 \mathrm{~mL}$ em $80 \%$ dasamostras anal isadas. Também não devem ser utilizadas para a irrigação de frutas ehortal iças que se desenvolvem rente ao solo, que não sejam removidas a cascaou películaprotetora, bemcomo suautilização para recreação e aqüicultura, pois apresentou concentração de coliformes acima do permitido pela Legislação.
Oliveira et al. (2002), ao analisar aságuas da bacia do Rio Paraguai, constataram que $85,7 \%$ das amostras de 3 estações apresentaram N M P acima de 2.400 $\mathrm{CF} / 100 \mathrm{~mL}$, mas em outros locais deste mesmo rio, encontraram teores menores de contaminação, enquadrando o rio na Classe 2 (1.000 N MP/ $100 \mathrm{~mL}$ de coliformes termotolerantes). Estes autores constataram que o NMP de coliformes totais e de termotolerantes aumenta à medida que o rio recebe efluente. No nosso trabalho foi constatado que a estação de coleta Ponto 1, do Rio São Lourenço, mesmo tendo a sua local ização situada anterior à região central dacidade, apresentou menores níveis decontaminação por coliformes, em relação às estações de coleta Ponto 2 e Ponto 3, porém demonstrou valores superiores a $1.000 \mathrm{NPM} / 100 \mathrm{~mL}$ de coliformes termotolerantes, o que enquadraria a água, quanto à balneabilidade, imprópria eclassificada na Classe4, destinadas à navegação e harmonia paisagística.

Duranteas coletas de verão, foram observados os maiores índices de contaminação por coliformes totais, principalmente nas estações de coleta Ponto $2 \mathrm{e}$ Ponto3(Fig. 3), asquaislocalizam-senaregião central da cidade. Isto pode decorrer do grande aumento populacional nacidadeduranteosmesesdeveraneio eao aumentonaeliminação doesgoto doméstico. Nas amostras referentes ao Inverno, foi possível observar um aumento na concentração de ambos, c. totais e c. termotolerantes, em relação àquelas analisadas durante o outono, mesmo considerando o aumento no volume de precipitações pluviométricas durante os meses de inverno e diluição da carga microbiana, já que o inverno nesta região apresenta-se bastante chuvoso. 
Tabela 1 - Número mais provável de coliformes totais e termotolerantes/ 100 mL de água do Rio São Lourenço, São Lourenço do Sul, RS.

\begin{tabular}{lccc}
\hline Estação/ A no & Local & $\begin{array}{c}\text { Coliformes } \\
\text { totais/ } \\
100 \mathrm{~mL}\end{array}$ & $\begin{array}{c}\text { Coliformes } \\
\text { termotolerantes/ } \\
100 \mathrm{~mL}\end{array}$ \\
\hline outono/ 04 & P1 & $9,0 \times 10^{3}$ & $<3$ \\
& P2 & $9,3 \times 10^{3}$ & $1,5 \times 10^{3}$ \\
inverno/ 04 & P3 & $1,5 \times 10^{4}$ & $4,3 \times 10^{3}$ \\
& P1 & $5,0 \times 10^{3}$ & $4,8 \times 10^{3}$ \\
primavera/ 04 & P2 & $7,6 \times 10^{4}$ & $6,7 \times 10^{4}$ \\
& P3 & $2,1 \times 10^{4}$ & $5,0 \times 10^{3}$ \\
& P2 & $1,3 \times 10^{4}$ & $2,3 \times 10^{3}$ \\
verão/ 04 & P3 & $2,3 \times 10^{4}$ & $4,9 \times 10^{4}$ \\
& P1 & $2,4 \times 10^{5}$ & $1,4 \times 10^{4}$ \\
& P2 & $1,6 \times 10^{6}$ & $2,1 \times 10^{4}$ \\
outono/ 04 & P3 & $1,2 \times 10^{6}$ & $2,3 \times 10^{4}$ \\
& P1 & $2,3 \times 10^{4}$ & $4,9 \times 10^{3}$ \\
& P2 & $4,3 \times 10^{4}$ & $4,0 \times 10^{2}$ \\
& P3 & $2,3 \times 10^{4}$ & $2,3 \times 10^{3}$ \\
\hline
\end{tabular}

A Resolução $n^{\circ} 357$ do CON AMA de 2005 classifica as águas doces em classe especial, destinadas aoabastecimento paraconsumo humano, à preservação dos ambientes aquáticos; em classe 1, à aquelas destinadas ao abastecimento humano, após tratamento convencional, àrecreação decontato primário, àirrigação dehortal içasenão excedendoumlimitede 200 coliformes termotolerantes por $100 \mathrm{~mL}$ em 80\% das amostras anal isadas; em classe 2, águas destinadas ao abastecimento para consumo humano, após tratamento convencional, à proteção as comunidades aquáticaseàrecreação decontato primárioeirrigação de hortaliças, não devendo ultrapassar o limite de
1.000 coliformestermotolerantes/ $100 \mathrm{~mL}$ em $80 \%$ das amostrasestudadas. A quel as enquadradasnaclasse 3, são destinadas ao consumo humano após tratamento convencional ou avançado, à pesca amadora, à recreação de contato secundário eà dessedentação deanimais, sendoquecoliformestermotolerantesnão devem ultrapassar um limite de $2.500 / 100 \mathrm{~mL}$ em $80 \%$ das amostras anal isadas e por último, em classe 4, águas destinadas à navegação e harmonia paisagística. Esta classi ficação sempre deverá observar os padrões de bal neabilidade previstos na Resolução CONAMA n²74, de 2000.

N as 3 estações decoleta avaliadas nestetrabal ho, as águas foram consideradas impróprias quanto à balneabilidade, pois apresentaram coliformes termotolerantes em 93\% das amostras analisadas, e com val ores acima do que determina a legislação, podendo ser classificadas na classe 4 destinada à navegação e harmonia paisagística. 0 ponto 1 , após tratamento adequado poderá ser utilizado para o consumo humano eabastecimento da cidade.

\section{CONCLUSÃO}

Os dados mostraram queo Rio São Lourenço está sofrendo impacto em sua qual idade, principalmente através da entrada de esgoto doméstico, pela alta concentração de coliformes encontrada. Os resultados obtidos apontam a água do Rio São Lourenço comoumfator derisco àsaúdehumana, umavez que, no grupo de microrganismos avaliados, são encontrados agentes infecciosos envolvidosem enfermidades como diarréia e infecções urinárias. É necessário o desenvolvimento de ações preventivas com intuito deesclarecer a populaçãolocal sobreos riscosàsaúde queapresençado esgoto doméstico representa. Existe

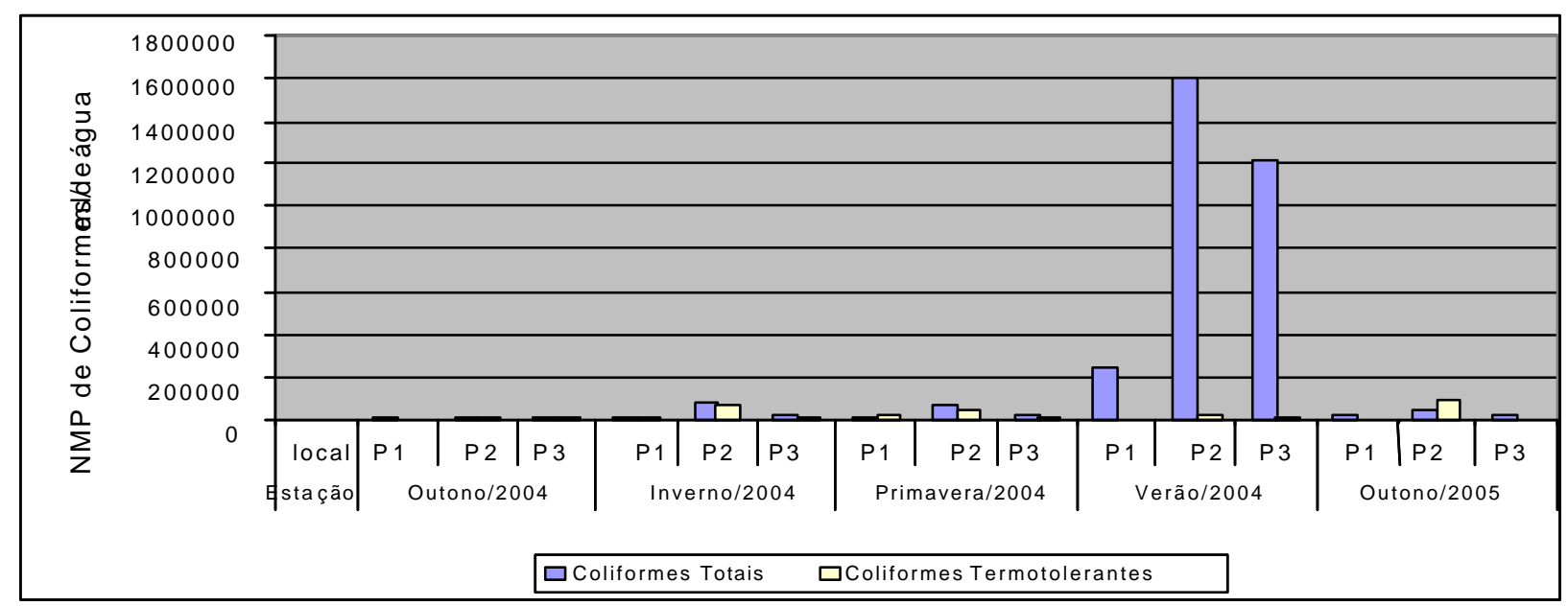

Fig. 3-Variação sazonal deColiformesTotaiseColiformesTermotolerantesno Rio São Lourenço, em São Lourenço do Sul, RS. 
a necessidade de preservar as fontes deágua, o combate à entrada de esgoto clandestino nas galerias pluviais e desenvolver técnicas de tratamento de efluentes daCidadedeSão Lourenço doSul. Estessão instrumentos necessários para diminuir ao máximo osriscosrelacionadosàsaúdepúblicanesteambiente.

REFERÊNCIAS

Amaral, L.A.; N ader Filho, A.; Rossi Junior, O.D.; Ferreira, F.L.A.;BARROS, L.S.S.Águadeconsumohumanocomo fator derisco à saúdeem propriedades rurais. R evista de Saúde Pública, v.37, n.4, p.510-514, 2003.

Barrell, R.; Benton , C.; Boyd, P.; Cartwright, R.; Chada, C.; Colbourne, J.; C ole, S.;C olley,A.;D rury,D.; G odfree, A.; Hunter,P.; L Ee, J.; M achray,P.; N IChOls, G.; Sartory, D.; SELLWOOD, J.; W ATKINS, J. TheM icrobiology of Drinking Water - Part 1 - Water Quality and Public Health. Methodsfor theExamination ofWatersand Associated Materials. Environment A gency, 2002, 50p.

Brasil. Consel ho Nacional do Meio Ambiente (CONAMA) - Resoluções no 357 de 2000. Disponível em: Łttp:/ / www.mma.gov.br/ conama/ >.A cessoem:28abr. 2005.

Byamukama, D.; Mach, R.L.; Kansilme, F.; Manafi, M.; FARnLeITNER, A.H. Discrimination Efficacy of Fecal Pollution Detection in Different A quatic $\mathrm{H}$ abitats of aHigh-AltitudeTropical Country, Using Presumptive Coliforms, Escherichia coli, and Clostridiumperfringens Spores. A pplied and Environmental M icrobiology, v.71, n.1, p.65-71, 2005.
CostA, J.S. N avegadores da Lagoa dos P atos: a saga náutica deSão Lour enço do Sul. Hofstëtter, 1999, 232p.

Oliveira, M.D. de; Calheiros, D.F.; Santos, M.B.F.; Costa, M.S.; BARBOSA, D.S. Q ualidade da água em corpos d'água urbanos das cidades deC or umbá eL adário enoR ioP araguai, M S. Corumbá, MS: Embrapa Pantanal, 2002. (Circular Técnica $n$. 36).

Ringuelet, R.A. E cología acuática continental . Buenos Aires: Eudeba Editorial, Universidade de Buenos Aires, 1962. p.82.

Shibata, T.; Solo-Gabriele, H.M.; Fleming L.E.; Elmir. S. Monitoring marinerecreational water quality using multiple microbial indicators in an urban tropical environment. W ater Research, v.38, p.3119-3131, 2004.

Silva, N. dA; Junqueira, V.C.A.; Silveira, N.F.A. M anual de métodos deanálisemicrobiológica dealimentos. SãoPaulo: Varela, 1997. p.1-119.

SOARES, B.J. \& MAIA, F.C.A. Á gua: microbiologia etratamento. Fortaleza: Edições UFC, 1999.

Solo-Gabriele,H.M.;W olfert,M.A.;Desmarais,T.R.;Palmer, C.J. Sources of Escherichiacoli in a Coastal Subtropical Environment. A pplied and Environmental M icrobiology, v.66, n.1, p.230-237, 2000.

VoN SPERLING, M. Introdução à qualidade das águas e ao tratamento de esgotos. 2.ed. Belo Horizonte: DESA/ UFMG,1996. 243p.

Recebido em 13/ 2/ 06 Aceito em 22/ 5/ 06 